Hillstrom, K. \& Hillstrom, L. C. (Ed.). (1988). Encyclopedia of small business A-I (1st ed.,Vol 1).

Hunt, S. (2007). Different Types of Staffing Assessments. In Hiring Success: The art and science of staffing assessment and employee selection (pp.39-78). San Francisco, CA: Pfeiffer.

Mirabile, R.J. (1997). Everything you want to know about competency modeling. In Training and development (pp.73-77).

Richards, R. A. (n.d.). Hiring right. Retrieved April 8, 2008, from http://classweb. gmu.edu/cwright5/320/Selection/HiringRight.pdf

Rodriguez, A. (2005). Critical Factors in Hiring, Promoting, and Designing Job Descriptions for Strategic Project Managers. In UMI microform (pp.61-65). Ann Arbor, MI: Proquest Information and Learning Company.

Ruane,J.M. (2005). Essentials of research methods:A guide to social science research. Maldan, MA: Blackwell Publishing

Schermerhorn, J. R., Hunt, J. G., \& Osborn, R. N. (1997). Organizational Behavior (6th Ed.). New York: John Wiley \& Sons.

Survey results detail what top entry level employers want most. (2008, March 27). Retrieved April 8, 2008, from http://www.collegegrad.com/press

The interview process: selecting the "right" person. (n.d.). Retrieved April 8, 2008, from http://print.smallbusiness.findlaw.com/employment-employer/ employment-employer-hiring-interview-selection.html

Theresa Minton-Eversole (2007, December). Class of '08 Expecting High Demand. HRMagazine: 2008 HR TREND BOOK, 34,37. Retrieved June 7, 2008, from ABI/INFORM Global database.

Wilkinson, A. (1988). Empowerment: theory and practice. Personnel review 27 (1): 40-56. Retrieved on 2007-10-17.

Yusko, K. \& Goldstein, H. (2006). Strategic Staffing: Talent acquisition in the 21st century. In R. R. Sims (Ed), Human resource management: Contemporary issues, challenges, and opportunities (pp. 175-226). Charlotte, North Carolina: Information Age Publishing.

\section{African American Vernacular English}

\section{LaWanda Lewis}

Mentor: Dr. Roberta Lavine, Associate Professor

Languages, Literatures, and Cultures

University of Maryland, College Park

\section{Abstract}

African American Vernacular English (AAVE) causes reading problems for majority of the African American students who speak it. There is a strong concern of whether African Americans will perform adequately on the job front, due to low reading levels (Rickford, 1999). Although AAVE is a dialect shared by many African Americans, they need to be able to have proficient Standard English in order to move forward and become successful in America (Rickford, 1999). African Americans have been, and still are performing poorly in reading and have very low academic achievement throughout the nation (Rickford, 1999). Bronfenbrenner's (1979) Ecological Systems theory was use to determine possible factors contributing to the reading problems that AAVE speaking children face when trying to learn Standard English. For the purposes of this inquiry, of the four systems in the theory only the microsystems and mesosystems were analyzed. In order to gain a healthy understanding of African American Vernacular English and majority of its topics, an extensive amount of literature review and scholarly articles read and analyzed. The results discovered from the literature were that there are three main reasons why AAVE speaking students have reading problems.

\section{Problem Statement}

While these issues are important, this paper will focus on AAVE and education. Although AAVE is a dialect shared by many African Americans, they need to be able to have proficient Standard English in order to move forward in America (Rickford, 1999). African Americans have been, and still are performing poorly in reading and have very low academic achievement throughout the nation. Speaking AAVE is a contributing factor to the lack of advancement in academics in African American students (Rickford, 1999). Several experts such as Rickford (1999), Baratz (1969), Granger (1976), and Stewart (1969) have declared that the best thing to do to help solve this problem is to reach African American students where they are, meaning, teach them Standard English using their own dialect as a foundation. However, this suggestion has not been highly regarded by many people as the best method.

\section{Purpose of Inquiry}

The purpose of this paper is to explain some of the reasons AAVE speaking students are hindered when learning Standard English. This paper also supports 
the recommendations of previous researchers in teaching Standard English using the African American Vernacular English dialect as a foundation. This inquiry will address the following questions:

1. What are the reason speakers of AAVE are hindered when trying to learn Standard English?

2. Why do people disagree with using the foundation of dialects to teach standard languages?

3. Why should instructors use the foundation of dialects to teach standard?

\section{Summary of Theoretical Framework}

Several theories could be used as framework to observe the reading and poor academic achievement problems in the African American communities to gain different perspectives. However, for this inquiry, Bronfenbrenner's Ecological Systems theory will be applied to examine the African American students' educational problems.

Bronfenbrenner believed in order to understand how humans develop the entire ecological system in which the person grows must be considered (Bronfenbrenner, 1979). The Ecological Systems Theory implies that a system of relationships form a child's environment and influences the child's development (Bronfenbrenner, 1979). The theory explains four complex systems that effect the child's development. The four systems are the microsystem, mesosystem, exosystem, and the macrosystem. The microsystem refers to families, classrooms, neighborhoods and other primary environments that a child operates in (Brofenbrenner, 1979). The mesosystem refers to the processes taking place between two or more microsystems. The exosystem is the environment that the child is not directly involved in but has an affect on the child anyway, such as the child's parent's workplace (Brofenbrenner, 1979). The macrosystem identifies the larger cultural context that the child lives in. This layer contains laws, cultural customs, and values (Brofenbrenner, 1979). Figure 1 in the appendix will assist with better understanding of the four systems in the Ecological Systems theory.

Although the Ecological theory consists of four systems, for the purposes of this inquiry, the focus will be on the microsystem and mesosystem. As mentioned before, the mesosytem pertains to the interactions between two or more microsytems in the child's environment (Bronfenbrenner, 1979). For example, the linkage between school and the community. This theory explains when the microsystems in the child's environment have compatible expectations; the child's development is rather easygoing and balanced (Cole \& Gauvin, 2001). In the same view however, when the microsystems' expectations conflict, the child's development becomes difficult and unbalanced (Cole \& Gauvin, 2001).

\section{Literature Review}

Much research has been conducted on African American Vernacular English, most notably on the areas mentioned below. This portion of this paper will present what the literature of several earlier researchers on AAVE have to say about the different topics and issues concerning the dialect. These topics discussed in the literature review are important because they give a better understanding about African American Vernacular English. The ideas and statements used in the literature review deal with AAVE and the people who use it, the people who educate its users, and the experiences and findings of people who have studied it.

\section{Standard English and Dialect}

The language that is used most by educated speakers of a given region to carry out their important academic, economic, and political business is considered the standard for that region (Dandy, 1991). In the United States of America, English is considered to be the standard language. Standardized English has formal and informal language. Although informal standardized English is usually spoken, both the formal and informal are considered to be "standard language," or "standard English" (SE) or "educated English." On the other hand dialects are considered to be nonstandard. A dialect is a variation of a particular language (Dandy, 1991). Dialects are usually regionally or socially set apart from other dialects of the same language by differences in lexical, phonological, and grammatical rules. Everyone has been conditioned to have some kind of a dialect either through social groups, community or a specific region where they live (Daniels, 1998).

The most known descriptor of dialects in America is geographical location. This means that people can recognize what part of the country other people are from because of their dialect. For example, a characteristic of citizens in New England region of the United States is that they usually drop the letter " $r$ " in words (pahk the cah in Hahvahd yahd) meaning (park the car in Harvard yard). Speakers of the New England dialect also use the word bubbler for drinking fountain (Daniels, 1998). Unluckily, dialects have been labeled as a poor style of language (Dandy, 1991). This is unfortunate because a dialect is no more than a peculiar way of vocalizing an already agreed upon language. People with dialects usually have their own idiolect as well (Dandy, 1991). Idiolects are individual personal dialects (Dandy, 1991). Figure 2 in the appendix is Dandy's illustration of how language can vary on a regional, social, and personal level.

African American Vernacular English (AAVE) is the dialect spoken by the majority of African Americans in America. Dandy (1991) stated "The language is alive and well and is spoken everywhere African Americans reside in America" (p.12). Although AAVE is spoken everywhere African Americans live, a couple of exceptions apply to this situation. One is that not all African Americans speak the dialect all of the time. These individuals most likely inherently understand the idea of sociolinguistics (Dandy, 1991). Simply speaking, they understand that certain types of language have a specific impact in different places in society.Therefore, they 
know when where and how to use their dialect, so they may be bidialectal (Dandy, 1991). For example, Dandy uses the story of her daughter Roslyn to explain this circumstance. Roslyn learned to talk when she lived in Philadelphia and acquired her mother's dialect, who also grew up in Philadelphia. Then when Roslyn was almost five, she moved to Savannah, Georgia and developed the dialect of her peers and teachers. In an effort to fit in with different people, she learned to shift her speech depending upon whom her audience was (Dandy, 1991). Dandy (1991) also stresses, "Now, as an adult, she switches her pronunciation, grammar, and vocabulary to the most acceptable form depending upon the situational requirement" p.v-vii).

Another exception prevalent in speakers of AAVE is that everyone does not use every feature of the dialect (Dandy, 1991).This means that although you may have the opportunity to listen to some African Americans use AAVE, do not expect that they will use every rule or feature that applies to the dialect; they may only use a select few. The features of the dialect are more common among working class than middle class speakers and more frequent among adolescents than the middle aged; more in informal contexts rather than formal ones (Rickford, 1999). Both of the exceptions about AAVE speakers are important to understand, but one thing is for certain, although all African Americans do not use the dialect, the majority comprehend its features (Dandy, 1991).

\section{Origins of AAVE}

have been preserved in the language of African Americans (Dandy, 1991). The debate on the origin of African American Vernacular English is revolves around comparative data from the English adaptation in the Diaspora, Caribbean Creoles, and other varieties of English (Green, 2002). Because information is limited, different proposals on how the dialect actually began and evolved are regarded. As additional research becomes available, other ideas about the origin of AAVE have been developed (Green, 2002).

People who share the same culture generally decode or understand the messages of symbols, behaviors and other objects the same or in like ways (Dandy, 1991). Our worlds are interpreted through our cultures. The ways in which people think, learn, and even the way in which they talk, all revolve around their culture. It is a way in which people identify and interact with one another (Dandy, 1991). According to Dandy (1991), African Americans participate in many community activities and cultural traditions that are similar throughout America and the Diaspora. Dr. Hilliard, an expert of kemetology, stated in 1985, "Africans in the African Diaspora, including the Americans and the Caribbean retained and still retain varying degrees of African culture. The culture is reflected in family patterns, language, religious belief systems, artistic creativities, etc." (p.155). With respect to Hilliard's statement, the main reason that many African Americans have many similar community activities and traditions is because they share an identical culture that has descended and resonated in them from the first African slaves who were brought to America and the rest of the "New World." Since, these slaves were forced to comprehend and assimilate the
English language, it has been suggested that AAVE has limited features that are similar to general English (Green, 2002). This view of the origin of AAVE suggests that the vernacular is configured and directly related to West African languages such as Kikongo, Mande, and Kwa. This perspective is known as the "substratist hypothesis" because it implies that the West African languages are the supporting basis for AAVE's sentence and sound structure (Green, 2002).

In contrast Harrison, an early American dialect scholar, views the speech of African Americans as a low quality and childish form of English (1884). In his essay "Negro English" he says, "Much of his talk [the Negro's] talk is baby talk ... the slang which is an ingrained part of his being as deep dyed as his skin ... the African, from the absence of books and teaching, had no principle of analepsy in his intellectual furnishing by which a word, once become obscure from a real or supposed loss of parts or meaning, can be repaired, amended, or restored to its original form" (Harrison, 1884, p.233). That is, until in 1949, L.D Turner challenged Harrison's statement after mastering several African languages and dialects (Turner, 1949). He stressed:

When the African came to the United States and encountered in English certain sounds not present in his native language, he did what any other person to whom English was a foreign language would have done under similar circumstances- he substituted sounds from his own language which appeared to him to resemble most closely those English sounds which were unfamiliar to him... The English inter-dental fricative th does not exist in the Gullah and nor in the West African languages included in this study. When pronouncing English words containing this sound, both the Gullah speaker and the West African substitute [d] and [t], respectively, for the voiced and voiceless varieties of $i t$. (Turner, 1949, p.245)

A clear example to support Turner's statement is how many African Americans even today still say words such as "dem," "den," "dis," and doz" instead of "them," "then," "this," and "those" (Dandy, 1991).Africans were restricted from learning how to read and write, therefore, many of the cultural African contributions, especially in the verbal and nonverbal traditions of communication

Another view on the origin of AAVE is the idea that the dialect began as a Creole such as Jamaican Creole and Gullah, which are spoken off of the coast of South Carolina and Georgia (Green, 2002). A Creole is a language that develops from a pidgin; it is the mother tongue that originates from contact between two languages. The "Creole hypothesis" was introduced to provide another perspective on the development of AAVE because the vernacular shares patterns with Creole varieties of English such as Jamaican Creole and Gullah (Green, 2002). For instance, the Creole hypothesis focuses on the similarities between the copula absence in AAVE and numerous Caribbean Creoles (Rickford, 1999). Copula is an equating verb that links the subject with the complement of a sentence, such as the verb "be." American linguist, William Labov (1972), says that one of the most challenging and complex problems with Black English is the appearance and disappearance of the copula. Labov (1972) also states, "It is well known that BEV [Black English 
Vernacular] frequently shows the absence of be in a variety of syntactic environments ... The French Creole of the Caribbean (Soloman, 1966) shows the same pattern (13-14), and so does the English Creole of Trinidad (15-16)" (p.67-68). The more research we see on the absence of the copula in AAVE the more evidence we have for the argument of its Creole origins (Green, 2002).

\section{Many Labels for One Dialect}

Although the term African American Vernacular English was chosen to refer to the dialect of African Americans in this research paper, there are many expressions utilized to refer to the dialect. In fact, several words and phrases that are commonly known. These terms are Negro dialect, Nonstandard English, Nonstandard Negro English, Negro English, American Negro speech, Black communications, Black dialect, Black folk speech, Black street speech, Black language, Black English, Ebonics (derived from the words ebony and phonetics),Vernacular, Black Vernacular English, Inner-city English, Afro American English, African American English, African American Language and African AmericanVernacular English (Dandy, 1991; Green 2002). Many of the labels given to the dialect contain the word English to acknowledge that some of the characteristics in the dialect are similar and common to those of different varieties of English (Green, 2002).

In some instances, the word English has been eliminated to emphasize African and Creole relations (Green,2002). The phrase Black Communications was coined by Hoover (1985). Hoover suggested Black Communications (BC) because she stresses that the dialect is more than just speech, but a whole system of communication (Dandy, 1991). The system of Black Communications includes speech codes, speech acts, style, nonverbal behaviors, special speaking behaviors, sociolinguistic rules for speaking, and moral teachings (Dandy, 1991).Baugh, used the phrase "black street speech" in his 1983 book, where he analyzed "one slice of black American culture, namely, the common dialect of the black street culture" (Baugh, 1983).

African American psychologist, Robert Williams, coined the term "Ebonics" in 1973. He intended that the words be used to describe the collection of languages spoken by black people in the United States and the Caribbean (Green, 2002). Many of the names given to the dialect have changed over the course of years since the 1960s, but they all refer to the same dialect (Green, 2002).

\section{AAVE's Sociolinguistic Issue}

The usage of African American Vernacular English in professional settings tends to bring about negative attitudes. When speaking AAVE or any other form of non Standard English in professional arenas, the speaker, many times is perceived or evaluated as being incapable of communicating effectively (Green, 2002). Baugh explains that hirers pursue articulate blacks (and other minorities) for their management trainee positions, which ultimately means that they have a negative judgment about AAVE and other nonstandard English. AAVE, especially is considered to be unintelligible, incoherent, non-fluent and illogical speech (1983). If an AAVE speaker is confronted in a situation where the employer thinks negatively about their vernacular, the important thing that the AAVE speaker should remember is that they are expected to shift their dialect to the standard because the norm for that professional setting is the standard. Green (2002) goes on to say:

Nonstandard English speakers should adjust their speech to the standards of their employers because, after all, they are offering services as representatives of the company, and, as a result, they should strive to be a representative voice of the company. Along these lines, employees have the obligation to speak what the employer deems appropriate for the company, and the employer has the power to demand a particular variety of language. The message is that AAE [African American English] is not appropriate language for use in a professional setting. (p.223)

\section{AAVE and Education}

In late 1996, the Oakland School District in California directed the nations' attention to the disappointing truth about the massive educational failure within African American communities across America (Rickford, 1999). In Oakland at that time, $53 \%$ of its school district population was African American and they represented $80 \%$ of all suspended students and had the lowest grade point average, which was approximately a C-. The irony of this situation is, since 1981, Oakland's original aim was to use the Standard English Program (SEP) to help students learn to the standard using their vernacular (Rickford, 1999). Whatever was going on in the classroom, it was not working. Rickford (1999) states, "the fact of the matter is that the status quo with respect to the teaching of African American children in American elementary, middle, and high schools is far from satisfactory" (p. 331). When students of any ethnicity do well in English, they usually do well in other subjects, but when they do not do well in English, their performance in other subjects are usually not well either (Rickford, 1999). African Americans have been performing poorly in reading for years. Oakland is not the only city where African American children face problems in reading. City after city in the United States have reported in substantial numbers that the reading achievement for black children is unacceptably below the norms (Shuy \& Baratz, 1969). Green (2002) also states, "the reading scores for African Americans in inner cities are well below the mean, below the basic level or reading level for a particular grade" (p. 228). The National Assessment of Educational Progress reports that in the years 1992, 1994 1998 and 2000, African American students' grades were consistently dropping as they advanced to the next grade level and persistently trailed behind the grades of white students (Green, 2002). This can be seen in Table 1 in the Appendix.

A teacher's reaction or response to the vernacular has a monumental impact on the reading success of African American students (Rickford, 1999). Teachers usually have inexcusably negative attitudes towards AAVE and students who speak it. When teachers present negative attitudes, sometimes it can lead them to hold low expectations already in mind for these students (Rickford, 1999). As result, they may have the students put in learning disability and special education classes 
and this restrains the students' academic performance (Rickford, 1999). When the teacher gives off a negative attitude toward an AAVE speaking student, the student often becomes offended and refuses to cooperate and continue in the participation of their own education. Therefore, many times, reading failure in African American students is a mere product of miscommunication between the teacher and student (Labov, 1970).

The miscommunication starts with the teachers. When they demean and discourage the use of the students dialect, completely ignoring and failing to understand that it is a part of the students culture, they can easily classify the students as deprived, disadvantaged, and nonverbal (Dandy, 1991). Baratz (1969) found out after reviewing literature, that educators of African American students were the first people to announce that the students were destitute, i.e. they couldn't talk, or their speech was filled with errors. Then following the educators, psychologists reconfirmed the same idea. However, when linguists like her examined the children, they had come to the conclusion that the students spoke a highly structured, highly developed language system that was in many ways different from Standard English (Baratz, 1969).

Additionally, the differences between African American Vernacular English and Standard English also contribute to the difficulty in learning to read (Dandy, 1991). Although the dialect is indeed a variation of English it has different rules in its structure (Dandy, 1991). As explain in a previous section of the paper, many of the phonological features in AAVE are distinct from Standard English. AAVE's plurality is expressed once in a sentence, whereas in SE, plurality can be expresses up to three times. For example, plurality in AAVE could be shown as "Now I got five cent" (Dandy, 1991, p. 49). The five in the sentence indicates that there is more than one cent. Possession in AAVE is also different. It can be shown by proximity where the owner's name comes before the object owned. For instance, "She over Mary house" (Dandy, 1991, p.49). In this sentence you know that the house belongs to Mary because her name precedes the object owned. However, in SE, the only way to show possession is to add 's after the owner's name. Two more very clear differences are in third person present tense, AAVE speakers usually retain the same form in person and number and in SE " $\mathrm{s}$ " is used in third person present tense.

Lastly, when "ed" is used to indicate past tense in SE, words stay in the same form in all tenses in AAVE (Dandy, 1991). Because of these significant differences in AAVE and SE, learning the Standard from persistent use of the dialect is not as easy as it may seem. Goodman (1969) states, "it is harder for a child to learn to read a dialect that is not his own than to learn to read his own" (p.14). What Goodman means is that since a child is accustom in using his dialect, learning to read what they already speak is much easier. Therefore, because African American students are not accustom to speaking the SE, it is much harder for them to learn to read SE.

Furthermore, African American students fear being rejected from their own speech community (Morgan, 2002). When students chose to use Standard English and tend to the demands of the non African American society, they risk losing community membership (Morgan, 2002). Many African American students think that speaking Standard English is a white person characteristic. So, when an AAVE speaking child chooses to use Standard English over the vernacular in their community they are often accused of trying to act "white" (Jones, 1998). Therefore, African American students sometimes encourage each other to speak incorrectly by teasing each other when they do speak Standard English (Jones, 1998).

\section{Findings from a Review of the Literature}

RESEARCH QUESTION 1:

What are the reason speakers of AAVE are hindered when trying to learn Standard English?

- A teacher's negative reaction and attitude toward the students' vernacular

- Differences between African American Vernacular English and Standard English

- The fear of rejection from their own communities if they choose to speak Standard English instead of the vernacular that the majority of community speaks.

\section{RESEARCH QUESTION 2:}

Why do people disagree with using the foundation of dialects to teach standard languages?

Most people disagree with this method because of the misconception that AAVE will be taught in the classroom. Another reason for disapproval of the method is because some people believe it supports the idea that African Americans are inferior, inadequate and it deepens the perception of disadvantaged Black youths.

\section{RESEARCH QUESTION 3:}

Why should instructors use the foundation of dialects to teach standard?

Instructors should use the foundation of dialects to teach the standard because the methods that are being used in the classroom today are not working and African American students are still declining in academics. Also, the method is effective and has different strategies for teaching. Last but not least, this method improves communication, unity, and encouragement between the teachers and students.

\section{Conclusions}

First, negative attitudes from teachers towards the usage of AAVE cripple the reading development in African American students who speak the vernacular. When teachers approach AAVE speaking children with negative attitudes often times they start a process of miscommunication between the student and themselves (Dandy, 1991). Also, when teachers have negative attitudes about the dialect speaking children they usually have low expectations for them, which then becomes a self fulfilling prophecy (Dandy, 1991). If AAVE were used in the classroom to teach the Standard English in the classroom, the children reading process should smoothen because the expectations from the mesosystem become more compatible. 
Second, teachers should not attempt to abolish the child's usage of the dialect because it is important for the communication in their community microsystem and it discourages the AAVE speaking child to participate in education. One way teachers tend to deal with the use of AAVE in the classroom is the strategy of eradication (Smitherman, 2000). The goal of eradication, is to erase the dialects traces by constantly correcting the AAVE speaking child when they use the dialect (Green, 2002). Smitherman (2000) says this correctionist approach is not a good method because often correcting grammar supercedes focus on attention to meaning and sense. Smitherman and Dandy go on to say that reading and speaking instruction for these students often includes correction that discourages the student and inhibits them in the classroom $(2000 ; 1991)$.

\section{References}

Baratz, J. C. \& Shuy, R.W. (Eds.), (1969). Teaching black children to read. Washington, D.C: Center for Applied Linguistics.

Baugh, J. (1983). Black street speech: its history, structure, and survival. Austin, TX: University of Texas Press.

Bronfenbrenner, U. (1979). The ecology of human development: Experiments In nature and design. Cambridge, MA: Harvard University Press

Bronfenbrenner,U.(2005).Making human beings human:Bioecological perspectives on human development. Thousand Oaks. Sage Publications

Cole, M. \& Gauvin, M. (2001). Readings on the development of children (3 ${ }^{\text {rd }}$ ed.). New York, NY: Worth Publishers.

Dandy, E. B. (1991). Black communications: Breaking down the barriers. Chicago, IL: African American Images.

Daniels, H. A. (1998). Nine ideas about language. In Clark, V. P., Eschholz, P. A. \& Rosa, A. F. (Eds.), Language: Readings in language and culture (6th ed.). Boston, MA: Bedford / St. Martins.

Goodman, K. S. (1969). Dialect barriers to reading comprehension. In J. Baratz \& R. W. Shuy (Eds.), Teaching black children to read (pp. 14-28). Washington, D.C: Center for Applied Linguistics.

Granger, R. C. (1976). The nonstandard speaking child: Myths past and present. Young Children, 31, 478-485.

Green, L. J. (2002). African American English: A linguistic introduction. New York, NY: Cambridge University Press.

Harrison, J. A. (1884). Negro English. Anglia: Journal of English Philology, 7, 232-79.

Harrison-Wright, K. (1987). The challenge of educational coalescence: Teaching nonmainstream English-speaking students. Journal of Childhood Communication Disorders, 11, 209-215.
Harrison-Wright, K. (1999). Enhancing bidialectalism in urban African America students. In C. T. Adger, D. Christian \& O. Taylor (Eds.), Making the connection: language and academic achievement among African American students (pp. 53-60). McHenry, IL: Center for Applied Linguistics and Delta Systems Co., Inc.

Hilliard, A.G. (1985). Kemetic concepts in education. In I.Van Sertima (ed.), Nile Valley Civilizations: Journal of African Civilization, 153-162.

Hoover, M. R. (1985). Ethnology of black communications. Journal of Black Reading/Language Education, 2, 2-4.

Labov,W. (1972). Language in the inner city. Philadelphia,PA:University of Pennsylvania Press

Meier,T. (2008). Black communications and learning to read: Building on children's linguistic and cultural strengths. New York, NY. Lawrence Erlbuam Associates.

Morgan, M. (2002). Language, discourse and power in African American culture. New York, NY. Cambridge University Press

Rickford, J. R. (1999). African American vernacular English. Malden, MA: Blackwell Publishers Inc.

Ruane, J. M. (2005). Essentials of research methods: A guide to social science research. Malden, MA: Blackwell Publishers Inc.

Stewart, W.A. (1969). On the use of Negro dialect in teaching of reading. In J. Baratz \& R. W. Shuy (Eds.), Teaching black children to read (pp. 156-219). Washington, D.C: Center for Applied Linguistics.

Turner, L. D. (1949). Africanisms in the Gullah dialect. Ann Arbor, MI: University of Michigan Press. 